\title{
Determinants of Individual Knowledge Innovation Behavior: A Perspective of Emotion, Knowledge Sharing, and Trust
}

\author{
Sihua Chen, Jiangxi University of Finance and Economics, China \\ Hua Xiao, Jiangxi University of Finance and Economics, China \\ Wei He, Jiangxi University of Finance and Economics, China \\ Jian Mou, Pusan National University, South Korea \\ Mikko Siponen, University of Jyvaskyla, Finland \\ Han Qiu, Jiangxi University of Finance and Economics, China \\ Feng Xu, Tianjin University, China
}

\begin{abstract}
With the upsurge of "emotional storm" in the field of organizational behavior, the studies on individual emotions in organizational context are rising. The relationship between emotions and knowledge innovation has attracted much attention by scholars. In particular, individual emotions may exert great effect on knowledge innovation whereas the mechanism is still unclear. Based on the emotional event theory, this paper constructs a model that explores the interaction of positive and negative emotions with individual knowledge innovation. Based on questionnaire data analysis, the results show that knowledge sharing partly mediates the relationship between positive emotion and knowledge innovation as well as the relationship between negative emotion and knowledge innovation; team trust accentuates the relationship between positive emotion and knowledge innovation as well as the relationship between negative emotion and knowledge innovation. The above findings are helpful to clarify the impact mechanism of emotions on knowledge innovation.
\end{abstract}

\section{KEYWORDS}

Emotion, Knowledge Innovation, Knowledge Sharing, Team Trust

\section{INTRODUCTION}

Knowledge innovation has become an important source of sustainable competitive advantage for organizations, enabling them to adapt to global competition and environmental uncertainty (Qu et al., 2015). It is an important value-addition for organizations and a key factor for regional economic development (Zou \& Zhu, 2020). Based on knowledge investment and experience accumulation (Gergana \& Durisin, 2007), knowledge innovation generates new technologies, new approaches, and new methods through knowledge acquisition, stimulation, sharing, collision, and integration. It is also the result of complex interaction of people at the individual-, team-, and organizational level (Peng et al., 2015). Organizations attempt to promote knowledge innovation by taking various measures, 
such as encouraging knowledge sharing, improving individuals' positive attitudes, and enhancing team atmosphere (Tsai et al., 2020; Walumbwa et al., 2011).

Prior research has confirmed the impact of psychological contract, leadership style, personal characteristics, and team atmosphere on knowledge innovation (Bilian et al., 2016; Deas \& Coetzee, 2020; Wu et al., 2020, 2021). In particular, the influence of individual psychology on knowledge innovation behavior has been widely studied (Van \& Meyers, 2015). However, the mechanism underlying this influence is not clear. Moreover, conclusions about the relationship between emotions and innovation are inconsistent (Davis, 2007). This is partly because of the different theoretical perspectives, but more importantly because researchers have failed to effectively test the boundary conditions between emotions and innovation. George and Zhou (2002) pointed out that the influence of emotions on innovation is dependent on specific conditions (George \& Zhou, 2002). Some scholars have also emphasized that innovative behavior is the result of interaction between the psychological and situational factors of the individual (Sun \& Van, 2015). Notwithstanding these findings, even from this perspective, there are issues that need to be further clarified, such as the internal transmission mechanism of the influence of emotions on individual knowledge and its boundary conditions. This hinders the development of relevant studies in psychology and restricts practical exploration in the field of management as well.

In practice, many innovative solutions and ideas are generated through knowledge transfer, knowledge exchange, and knowledge sharing (Liu et al., 2021). Some scholars have pointed out that knowledge sharing of employees is directly related to their innovation ability (Tu et al., 2016). In particular, employees who are good at sharing their tacit knowledge with others may perform better in terms of innovativeness (Lu \& Liang, 2009). As such, knowledge sharing is important to individual knowledge acquisition and innovation (Liang et al., 2016). In this sense, an individual's ability to obtain the new knowledge and break their own knowledge barriers through knowledge sharing is a necessary condition for innovation. For the above reasons, this paper uses knowledge sharing as a mediating variable.

Emotion can influence individual cognition and information processing (Lu \& Liang, 2009). According to the emotional events theory, an individual's emotional state may affect their motivation, behavior, and innovation performance (He et al., 2018; Weiss \& Cropanzano, 1996). At present, research on the influence of emotion on innovation is mainly from the perspectives of emotional dimension theory and the basic emotional theories. However, there are two main conclusions, which contradict each other: first, positive emotions promote innovation, while negative emotions hinder innovation (Wang \& Yu, 2019; Xiao et al., 2015); second, positive emotions hinder innovation while negative emotions are conducive to innovation (Fernández-Abascal et al., 2013). This contradiction is one of the problems that the present paper attempts to discuss. After a further study of the relevant literature, it is found that the main reason for the contradictory findings is the difference in the working mechanism of emotions. Therefore, it appears particularly important to explore the mechanism by which emotions influence innovation. Some scholars have discussed the moderating role of leadership factors, such as leaders' trust (Eastwood et al., 2012); however, these studies ignore the context of team trust, which may function as the boundary condition of such an influence mechanism.

Trust, which is based on an individual's positive expectation of another's behavior, is essentially an organizational behavior that can promote the interaction of two parties. The maintenance of trust relies on frequent interaction and face-to-face contact (George \& Zhou, 2007; Zara \& Waqar, 2018). Team trust is the psychological willingness of a team member to influence others and also the willingness to accept others' influence; it is a reflection of the interdependence among team members (Deortentiis et al., 2013; Kipkosgei et al., 2020); it is the core element necessary for improving the work quality of cross-functional organizations and stimulating team members' innovation ability. According to the social exchange theory, trust among team members represents a mutual behavior: when team members are used to trusting their colleagues, the innovation behavior of team members is significantly affected (Huemer, 2014). Erdem and Ozen (2003) found that trust improved a team's 
ability to identify and solve problems and contributed to team planning. Tsai (2001) pointed out that with strong team trust, employees were more likely to exchange resources and knowledge to improve the innovativeness of the team. Team members with higher trust are more likely to identify various uncertain elements in the development process. By means of mutual communication, discussion, and cooperation, they can avoid risks and enhance a sense of achievement and enthusiasm for innovation in the team (Kipkosgei et al., 2020; Tsai, 2001). In the context of strong team trust, team members improve the innovation performance of new products by enhancing the degree of knowledge sharing (Mayer et al., 1995). It can be seen that the effect of individual knowledge sharing on knowledge innovation varies with the level of team trust. Therefore, based on trust climate, this study selects trust as a moderating variable and further explores the moderating effect of trust on knowledge innovation from the perspective of the external organizational environment.

According to social information processing theory, an individual's psychology and behavior are not determined only by his or her needs and goals, but are also affected by the surrounding environment. This is because these environmental clues, particularly the team trust, provide social information that can influence and regulate people's psychology or behavior (Cao et al., 2016). Team trust is based on the team members' evaluation of the overall team environment. Team trust comprises various kinds of social information. Team members often consider team trust as a source of information clues and adjust their psychological state and behavior accordingly (Kim, 2019). Furthermore, based on the work demand-resource model proposed by Demerouti (2001), work resources have potential value for individuals. As a kind of work resource, team trust has a positive impact on people's work attitudes by facilitating recognition of the significance of work, making them more willing to improve the work process and break the current inherent norms.

In this study, this variable is placed at the individual level, and it refers to the perception of the team trust atmosphere by an individual. According to Costigan (1998), team trust dictates the team climate. It encompasses the individual's trust in leaders as well as in colleagues and senior managers. Furthermore, it is believed that team trust is based on the overall evaluation of the trust environment of the team by an individual member. A trusting team atmosphere facilitates communication between individuals and leads them to share knowledge more openly (Guo \& Zhao, 2017). Based on this, this study constructs a moderated mediation model of the influence of emotions on individual knowledge innovation. This expands knowledge of the influencing factors of individual knowledge innovation. Moreover, this study uncovers the process mechanism by which individual emotions influence individual knowledge innovation. Third, it clarifies the contextual characteristics of the influence mechanism.

\section{THEORETICAL FRAMEWORK}

\section{The Influencing Factors of Knowledge Innovation}

Knowledge innovation is the primary driving force for enterprise development. It is also an important factor for enterprises to overcome their competitors' competitive advantages, cope with market competition, and improve their competitiveness. Knowledge innovation is inseparable from human factors. Employees are the key elements necessary for knowledge innovation. Schuler (1989) emphasized that employees' awareness and sharing behavior could improve the effectiveness of implementation of innovation strategy. Currently, the improvement of knowledge innovation from the perspective of employees is the focus of enterprises. According to the emotional intelligence theory, emotion is conducive to adapting to different environments and solving problems encountered in work and life. Therefore, some scholars believe that emotion is one of the significant predictors of innovation (Kjersti et al., 2015). In addition, the generation of knowledge innovation requires individuals to have rich knowledge, experiences, and skills. However, the knowledge mastered by an individual is often limited. Therefore, individuals' ability to obtain the new knowledge needed for innovation through knowledge sharing within a team and to break existing knowledge barriers represent 
necessary conditions for the generation of knowledge innovation (Xiao et al., 2015). Knowledge is possessed by all departments, units, and individual employees. If other members of a team can learn, experience, and accumulate knowledge continuously through a knowledge sharing mechanism, knowledge innovation becomes easier to achieve (Zhao, 2020). Knowledge is highly personalized and situational, and the sharing process needs close contact and mutual learning. Therefore, team atmosphere, which includes team trust, is an important situational factor for knowledge sharing (Tu et al., 2017). In conclusion, this paper studies how individual emotions and situational factors affect knowledge innovation. It focuses on the mediating effect of knowledge sharing and the moderating role of team trust.

\section{The Theoretical Model}

Individual emotion is interpreted as an individual's perception of information of the external environment. When the external environment is safe, an individual will conduct divergent thinking and propose innovative solutions. When the external environment is threatening, an individual will carefully evaluate the environment and adopt conservative solutions (Xu \& Chen, 2018). Some studies have found that the influence of emotion on innovation is inseparable from interpersonal interactions such as knowledge sharing (Schwarz \& Clore, 2003). According to the SECI model of knowledge creation proposed by Japanese scholar Nonaka Takeuchi, individual knowledge innovation depends on the original knowledge structure and the amount of information the individual has absorbed. Furthermore, knowledge sharing provides the channel for the individual absorption of information. Based on their existing knowledge, individuals continuously absorb, understand, and digest information through knowledge sharing until the creation of knowledge is achieved (Nonaka, 1994). Tsai (2001) pointed out that the sharing and transfer of knowledge enables individuals to learn from others' successful experiences and methods to enhance their ability to innovate. Hansen (2002) proved that the higher the level of knowledge sharing among enterprises, the more rapid their development of new products. Applying resource-based theory, Ray et al. (1989) found that knowledge sharing was the key to enterprise knowledge innovation. In a positive emotional state, an individual's working mood is high and therefore can maintain a broad vision in a crisis, actively collect more knowledge, and be willing to share, which are all conducive to knowledge innovation (Tang et al., 2011). However, individuals in a negative emotional state tend to avoid dealing with problems and "muddling along" becomes their strategy of choice, which reduces the knowledge sharing behavior that is beneficial to organizational interests (Seth et al., 2013). Therefore, this paper explores whether the individual's emotional state affects knowledge innovation through the mediating role of knowledge sharing.

In addition, individual knowledge innovation is affected by many factors, among which team trust is undoubtedly an important situational one (Zhang et al., 2017). Team trust can effectively reduce conflicts and promote good communication between members, enabling them to cooperate with each other and generate team cohesion. Besides, it improves an individual's initiative to innovate and knowledge sharing behaviors (Hoegl \& Gemuenden, 2001; Kramer \& Tyler, 1996). Some studies have shown that team trust has a positive impact on knowledge innovation. Siacotos (1998) pointed out that team trust could effectively promote the formation of team cohesion and positive emotions and therefore improved the knowledge innovation ability of the organization. Hansen (1999) stated that when team members trusted each other, they would promote the exchange of information and knowledge and thus facilitate the improvement of knowledge innovation ability. Akgun et al. (2005) pointed out that mistrust among members would reduce the ability of the team to coordinate and complete tasks, and lead to a failure to improve team innovation ability. It is consistently found that trust plays an important role in team innovation. Mutual trust among team members and the maintenance of such trust have a direct impact on the improvement of team knowledge innovation. Team trust plays a moderating role in the effect of individual's emotional reactions on their work attitudes and behaviors (Hashim \& Tan, 2015). Based on this, team trust is considered a moderating variable and the authors construct a theoretical framework for this study (see Figure 1). Specifically, from the 


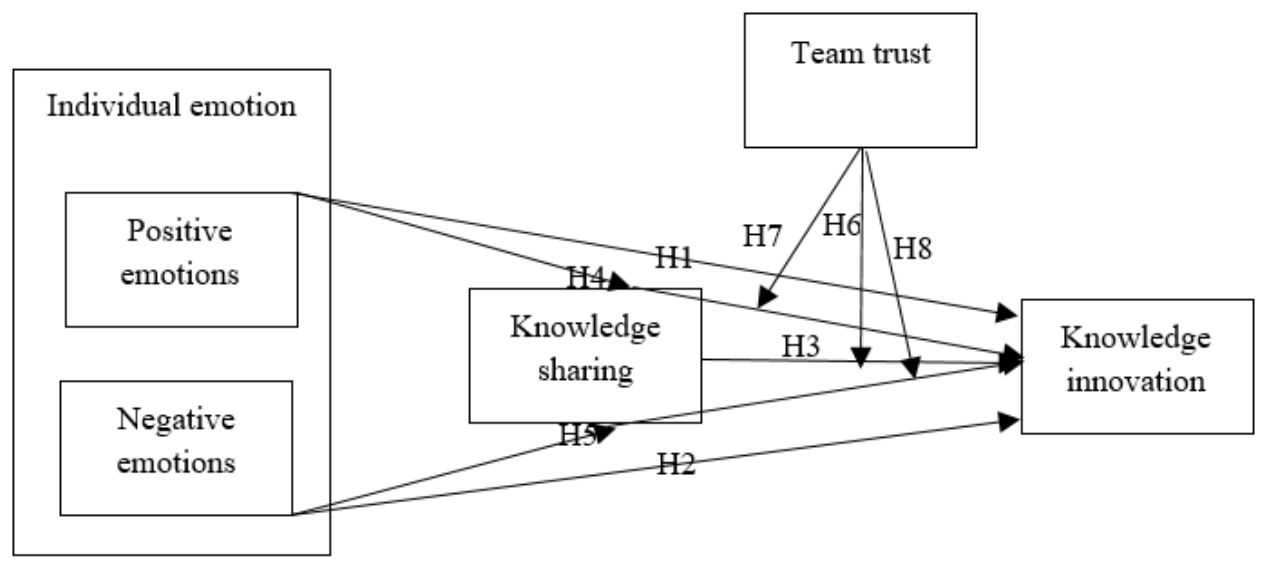

perspective of individual emotions, this paper explores the mechanism by which knowledge sharing influences knowledge innovation, that is, it examines the mediating role of knowledge sharing on the effect of individual emotions on knowledge innovation; furthermore, it explores how this mediating role changes with team trust levels.

\section{RESEARCH HYPOTHESES}

\section{Individual Emotion and Knowledge Innovation}

According to the emotional congruence theory, individuals in a positive emotional state recall a large amount of positive and diverse cognitive information (Reis \& Puente-Palacios, 2019), thus contributing to innovation performance (Shuhua et al., 2015). Based on the expansion construction theory of positive emotions, positive emotions affect individual innovation through the expansion of individual cognitive activities. Specifically, positive emotions can expand the scope of an individual's attention, promote the integration of all aspects of information in thinking about problems, and activate existing knowledge in the minds of individuals to a greater extent to make more information available for solving creative problems and conducting knowledge innovation (Xiao et al., 2015). As such, it can promote individual innovation. According to the cognitive flexibility improvement theory, positive emotions may weaken the internal control of attention resources and broaden an individual's attention span. The expansion of the attention span will reduce the ability of individuals to filter and suppress irrelevant information, which is conducive to the generation of more novel ideas (Buric \& Macuka, 2018). However, individuals with high negative emotions tend to have negative cognition of new things and new ideas, which reduces their work engagement (Rowe et al., 2007). This reduces their innovative behavior. Ashkanasy et al. (2002) found that an individual in a negative emotional state made decisions that are more conventional and had no novel ideas. Moreover, individuals with negative emotions often adopt a detail-oriented, bottom-up information processing method: this is conducive to the optimal solution of the problem because it focuses on the current situation or problem; however, it is not conducive to divergent thinking and hinders knowledge innovation (Davis, 2009). In conclusion, positive emotions can promote knowledge innovation while negative emotions negatively affect knowledge innovation (Seo et al., 2012). Based on this analysis, the paper proposes the following hypotheses: 
Hypothesis One: Positive emotions positively affect knowledge innovation.

Hypothesis Two: Negative emotions negatively affect knowledge innovation.

\section{Knowledge Sharing and Knowledge Innovation}

As the core of knowledge management, knowledge sharing has an important impact on innovation. Opinion sharing and accepting behavior may have an influence on the collision of individual thinking and subsequently affect innovation through interpersonal interaction (Cabrera et al., 2006). In particular, the degree to which individuals are willing to share unique information is regarded as a factor that influences the expansion of organizational thinking. Sharing unique knowledge will help individuals to recombine previous ideas, apply them to their existing work, and come up with new solutions. In a R\&D team, knowledge sharing can increase the knowledge stock of team members, improve their ability to undertake knowledge innovation, and generate cumulative innovation. Furthermore, knowledge workers in the network share knowledge to form a spiral upward development trend. At the same time, in accordance with the dynamic changes in the external market, knowledge workers update their knowledge in a timely fashion in order to provide sufficient intellectual support for innovation. Some scholars have proposed that there is a significant positive correlation between knowledge sharing and innovation performance (Reychav \& Weisberg, 2013). Based on the above analysis, the paper proposes the following hypothesis:

Hypothesis Three: Knowledge sharing positively affects knowledge innovation.

\section{The Mediating Role of Knowledge Sharing}

Reychav and Weisberg (2013) pointed out that knowledge has certain economic value. Knowledge sharing is not only an act of knowledge transmission and absorption, but also a process of communication. Among the factors influencing knowledge sharing, emotion has been paid an increasing amount of attention. Some studies have found that psychological incentives provided by organizations, such as comfort-oriented emotions, can increase employees' willingness to exchange knowledge, thus promoting employee knowledge sharing (Wang, 2016). In particular, positive emotions can promote tacit knowledge sharing (Stephens \& Carmeli, 2016). According to the emotional infection theory, the individual's emotions as expressed in the workplace may spread within the organization. Through mutual infection and transmission, this behavior can encourage employees to actively interact and communicate with each other and stimulate their willingness to share knowledge (Anand \& Gaur, 2019).

According to the emotional regulation theory, an individual may change their negative state or maintain a positive state through various actions and reactions. Therefore, when an individual is in a negative emotional state, he or she may initially attempt various actions to change that state. Helping others, such as sharing knowledge with others, may alleviate negative emotions. Cialdini (1976) proposed that sharing knowledge with others enabled individuals to overcome negative emotions and promoted good feelings. Individuals with negative emotions thus undertake knowledge-sharing behavior mainly because such behavior will bring satisfaction. Knowledge exchange, communication, and sharing with others and the use of integrated and transformed new knowledge can effectively improve knowledge innovation ability. Based on the above analysis, the paper proposes the following hypotheses:

Hypothesis Four: Knowledge sharing plays a mediating role between positive emotions and knowledge innovation.

Hypothesis Five: Knowledge sharing plays a mediating role between negative emotions and knowledge innovation. 


\section{The Moderating Effect of Team Trust}

The emotional experience and emotional expression of employees at work is an important part of the workplace behaviors. According to the emotional events theory, all kinds of events experienced by employees in their work will lead to individual emotional reactions, thus affecting employees' work attitude and behavior (Xu, 2015). Communication between groups in the workplace will generate emotions (Weiss \& Cropanzano, 1996). Knowledge sharing requires communication between individuals. In particular, when the group atmosphere is positive, individuals with high positive or negative emotions can improve the quality of information exchange, which is conducive to knowledge sharing. Then it can promote an individual's divergent thinking and make their views more fluent and original. For example, the psychological state of anger, depression, or indignation generated by negative emotions may stimulate individuals to explore reality, create strong self-reflection, and undertake persistent thinking, thus leading to higher innovation (Wang \& Noe, 2010). However, the literature on knowledge innovation points out that only by comprehensively considering the influencing factors and situation can it discover new characteristics. In addition, the single-level view of individual behavior research cannot explain how the group situation affects individual behavior and how individual psychology interacts with the group situation (Baas et al., 2008).

According to the expansion construction theory of positive emotions, emotions have an impact on innovation through group interaction process. For example, positive emotions can promote some interactive processes (inspired by others to continue to push forward, agree with others' opinions, merge views, etc.) and thus improve organizational knowledge innovation ability (Huang \& Luthans, 2015). The trust atmosphere of a team will promote interaction among team members. When a team is in a positive emotional state, the interaction frequency will increase and the quality of sharing will also be improved, which will easily lead to new ideas (Rhee, 2007). On the one hand, high team trust improves the potential for individuals to share knowledge and alleviate their negative emotions; on the other hand, high-quality sharing helps team members form an effective knowledge distribution map among them and encourages team members to conduct knowledge innovation. When the atmosphere of distrust and indifference diffuses within the team, individuals in a negative emotional state may make unremitting efforts to solve problems, come up with similar ideas, and seek out more original ideas to promote creativity by enhancing cognitive persistence (Lin et al., 2016). As such, it can be seen that emotions will produce different coping behaviors under different team atmospheres. In short, team trust can reduce the cost of interpersonal communication and increase the frequency and degree of knowledge exchange driven by individual emotional factors to improve the efficiency of knowledge innovation (Baas et al., 2013). Based on the above analysis, the paper proposes the following hypothesis:

Hypothesis Six: Team trust plays a positive moderating role in the positive relationship between knowledge sharing and knowledge innovation. The higher the team trust, the stronger the impact of knowledge sharing on knowledge innovation.

\section{Moderated Mediating Effect}

Situational factors may affect the relationship between individual work attitude and behavior (Cheung et al., 2016). For example, organizational climate can positively moderate the relationship between emotion and innovation (Judge \& Kammeyer-Mueller, 2012). From the above, we can see that knowledge sharing plays a mediating role in the relationship between emotion and knowledge innovation; this mediating role is affected by the level of team trust. Therefore, this paper argues that the mediating effect is affected by the level of team trust. Although negative emotions can reduce the level of individual knowledge sharing, in an atmosphere with a high level of team trust an individuals' confidence in their innovative ideas is enhanced and their attention and cognitive resources are shifted to knowledge innovation (Feng et al., 2019). Therefore, high team trust will weaken this negative 
relationship and have less impact on knowledge sharing, and therefore reduce the negative impact of negative emotions. When individuals have positive emotions and perceive that the team has a high trust environment, they will have a stronger willingness to engage in knowledge sharing, which is conducive to the optimal solution of problems, and show high innovation ability. Based on the above analysis, the paper proposes the following hypotheses:

Hypothesis Seven: Team trust plays a moderating role in the relationship between positive emotions and knowledge innovation, which is mediated by knowledge sharing: The higher the team trust, the stronger the mediating effect of knowledge sharing.

Hypothesis Eight: Team trust plays a moderating role in the relationship between negative emotions and knowledge innovation, which is mediated by knowledge sharing: The higher the team trust, the stronger the mediating effect of knowledge sharing.

\section{METHOD}

\section{Research Subjects}

The data were collected through a questionnaire-based survey. The respondents were team members engaged in basic research and technology development and application, and those with patent application records, or who have published papers in domestic and foreign journals, or believe they have knowledge innovation ability. Teams surveyed were from Nanchang, Beijing, Shanghai, Shenzhen, Guangzhou, Hangzhou, and Hefei. In issuing the questionnaires, in order to avoid possible data analysis bias, work-team based random sampling was conducted. The questionnaires were sent out and collected from March 2020 to September 2020. A total of 467 questionnaires were distributed and 450 questionnaires were collected from teams with patent application records, who had published papers, or they thought they had knowledge innovation ability. The authors adopted a combination of targeted sampling and random sampling. After excluding 11 questionnaires with incomplete or unqualified answers, 437 valid questionnaires were received, with a response rate of $97.1 \%$. Among the subjects, $53.1 \%$ were female and $46.9 \%$ were male; $5.3 \%$ of the subjects were under 18 years old; 49.7\% were between 19 and 30 years old; $27 \%$ were between 31 and 40 years old; and $15.1 \%$ were between 41 and 50 years old. Additionally, $92.4 \%$ of the subjects had a bachelor's degree or above' $44.9 \%$ of the subjects had worked for one year or less; $36.4 \%$ had worked for one to three years; and $18.8 \%$ had worked for three years or more.

\section{Measurement}

The scales used in this paper were all from papers published in reputable journals. Considering the particularity of the Chinese situation, all English scales were translated into Chinese based on strict standardized back-translation procedure. The relevant sentences and wording in the scale were adjusted according to the knowledge innovation situation. Based on the research topic of this paper, the revised scale is shown in Table 1. The questionnaires were collected on a seven-point Likert scale, where 1 indicates "totally disagree" and 7 indicates "fully agree."

Knowledge innovation. Knowledge innovation is the concentrated reflection of knowledge acquisition, knowledge absorption, and knowledge creation. According to Cohen and Levinthal (1990) and Lundvall (2001), and referring to the relevant research scale, five items were designed.

Knowledge sharing. Knowledge sharing was assessed by Bock et al.'s (2005) scale, which has four items.

Emotion. The Panas Emotion Scale was developed by Watson (1988). The original Panas questionnaire includes ten items to measure positive emotions. In this paper, we choose five items with the highest factor loading values for the measurement of positive emotions: "happy," "full of 
Table 1. Items and results of confirmatory factor analysis

\begin{tabular}{|c|c|c|c|}
\hline Indicator & Item & Factor loading & CR, AVE \\
\hline \multirow{5}{*}{$\begin{array}{l}\text { Knowledge } \\
\text { innovation } \\
\text { (KC) } \\
\text { Cronbach's } \\
\alpha=0.844\end{array}$} & $\begin{array}{l}\mathrm{KC} 1 \text { : I can effectively take advantage of the working } \\
\text { environment of team internal knowledge sharing. }\end{array}$ & 0.684 & \multirow{5}{*}{$\begin{array}{l}\mathrm{CR}=0.814 \\
\mathrm{AVE}=0.470\end{array}$} \\
\hline & $\begin{array}{l}\text { KC2: I can make partial revisions based on the absorbed } \\
\text { external knowledge. }\end{array}$ & 0.701 & \\
\hline & $\begin{array}{l}\text { KC3: I can integrate the external knowledge with the existing } \\
\text { knowledge. }\end{array}$ & 0.717 & \\
\hline & $\begin{array}{l}\text { KC4: I can absorb knowledge to develop new ideas and } \\
\text { thoughts. }\end{array}$ & 0.717 & \\
\hline & KC5: I can quickly find and share new ideas and opinions. & 0.596 & \\
\hline \multirow{4}{*}{$\begin{array}{l}\text { Knowledge } \\
\text { sharing } \\
\text { (KS) } \\
\text { Cronbach's } \\
\alpha=0.822\end{array}$} & $\begin{array}{l}\text { KS1: I often exchange working experiences and secrets of } \\
\text { success with members of the team. }\end{array}$ & 0.741 & \multirow{4}{*}{$\begin{array}{l}\mathrm{CR}=0.779 \\
\mathrm{AVE}=0.471\end{array}$} \\
\hline & KS2: I often share the ideas and inspirations within the team. & 0.679 & \\
\hline & $\begin{array}{l}\text { KS3: I will share new knowledge with team members after I } \\
\text { have learned it. }\end{array}$ & 0.645 & \\
\hline & $\begin{array}{l}\text { KS4: I will provide relevant information if requested by team } \\
\text { members. }\end{array}$ & 0.675 & \\
\hline \multirow{5}{*}{$\begin{array}{l}\text { Positive emotion } \\
\text { (AE) } \\
\text { Cronbach's } \\
\alpha=0.884\end{array}$} & AE1: I often feel happy at work. & 0.786 & \multirow{5}{*}{$\begin{array}{l}\mathrm{CR}=0.865 \\
\mathrm{AVE}=0.562\end{array}$} \\
\hline & AE2: I am often full of enthusiasm at work. & 0.775 & \\
\hline & AE3: I am often active at work. & 0.751 & \\
\hline & AE4: I often feel proud at work. & 0.738 & \\
\hline & AE5: I often have inspirations at work. & 0.698 & \\
\hline \multirow{5}{*}{$\begin{array}{l}\text { Negative } \\
\text { emotion } \\
\text { (DE) } \\
\text { Cronbach's } \\
\alpha=0.93\end{array}$} & DE1: I often feel angry at work. & 0.858 & \multirow{5}{*}{$\begin{array}{l}\mathrm{CR}=0.907 \\
\mathrm{AVE}=0.661\end{array}$} \\
\hline & DE2: I often feel annoyed at work. & 0.811 & \\
\hline & DE3: I often feel disgusted in work. & 0.865 & \\
\hline & DE4: I am often irritable at work. & 0.823 & \\
\hline & DE5: I often get mad while working. & 0.698 & \\
\hline \multirow{3}{*}{$\begin{array}{l}\text { Team trust } \\
\text { (CT) } \\
\text { Cronbach's } \\
\alpha=0.806\end{array}$} & CT1: I believe my team members are consistent in their work. & 0.774 & \multirow{3}{*}{$\begin{array}{l}\mathrm{CR}=0.742 \\
\mathrm{AVE}=0.495\end{array}$} \\
\hline & CT2: On the whole, I trust my team. & 0.628 & \\
\hline & CT3: I think the team members are always sincere with me. & 0.695 & \\
\hline
\end{tabular}

enthusiasm," "active," "proud," and "full of inspiration" In accordance with the scale developed by Forgays (1997), five items indicating negative emotion were designed.

Team trust. Team trust refers to the scale of Jong and Elfring (2010) and has three items.

\section{RESULTS}

\section{Construct Validity and Reliability}

In this study, SPSS 24 was used to test the reliability of each variable using Cronbach's $\alpha$ and the internal consistency coefficient. The items used in this study are all from the research literature. Before the development of the questionnaire, pilot test was performed. Unreasonable options were deleted and reasonable options were added. After several rounds of "test-analysis-add or delete options", 
Table 2. The correlation coefficient matrix and the square root of AVE

\begin{tabular}{|c|c|c|c|c|c|c|c|c|c|c|c|}
\hline & Mean & $\begin{array}{l}\text { Standard } \\
\text { deviation }\end{array}$ & Age & Education & $\begin{array}{l}\text { Position in } \\
\text { team }\end{array}$ & $\begin{array}{l}\text { Participation } \\
\text { time }\end{array}$ & $\mathbf{A E}$ & DE & KS & KC & CT \\
\hline Age & 2.61 & 0.909 & 1 & & & & & & & & \\
\hline Education & 2.27 & 0.67 & 0.037 & 1 & & & & & & & \\
\hline $\begin{array}{l}\text { Position in } \\
\text { the team }\end{array}$ & 1.75 & 0.697 & $0.215^{* *}$ & $0.109^{*}$ & 1 & & & & & & \\
\hline $\begin{array}{l}\text { Participation } \\
\text { time }\end{array}$ & 2.57 & 0.985 & $0.250^{* * *}$ & $0.125 * *$ & $0.182^{* * *}$ & 1 & & & & & \\
\hline $\mathbf{A E}$ & 5.79 & 0.90 & $0.136^{* *}$ & -0.094 & $0.218^{* *}$ & 0.072 & $(0.750)$ & & & & \\
\hline DE & 2.96 & 0.95 & $-0.178^{* *}$ & 0.091 & -0.027 & -0.057 & $-0.376^{* *}$ & $(0.813)$ & & & \\
\hline KS & 5.53 & 0.89 & $0.150^{* *}$ & $-0.096^{*}$ & $0.097^{*}$ & $0.108^{*}$ & $0.446^{* * *}$ & $-0.325^{* * *}$ & $(0.696)$ & & \\
\hline KC & 5.60 & 0.91 & 0.088 & $-0.096^{*}$ & 0.1061 & 0.003 & $0.382 * *$ & $-0.283^{* * *}$ & $0.647^{* * *}$ & $(0.704)$ & \\
\hline CT & 5.57 & 0.82 & $0.105^{*}$ & $-0.104 *$ & -0.063 & 0.006 & $0.525 * *$ & $-0.265^{* * *}$ & $0.693^{* *}$ & $0.692^{* * *}$ & $(0.686)$ \\
\hline
\end{tabular}

Note: Values in the brackets are the square root of AVE; *denotes $p<0.05 ; * *$ denotes $p<0.01$.

the final items were determined. As such, the questionnaire has high content validity. Considering that differences in positions and cultures may affect the validity of the questionnaire, confirmatory factor analysis (CFA) was carried out to evaluate the validity of the scales using mplus8.3 software. The reliability and validity of the scale are shown in Table 1 .

The reliability analysis showed that the internal consistency coefficient of each variable is greater than 0.8 , which indicates good internal consistency. In this study, mplus8.3 was used for CFA and to test the constructive reliability (CR) of potential variables in this study. The results showed that the $\mathrm{CR}$ of each variable was above 0.5 , which indicates good $\mathrm{CR}$. In this study, the square root of average variance extracted (AVE) of each variable was greater than or close to 0.5 . In conclusion, the results indicate good reliability and internal consistency.

In this paper, CFA is used to test the convergence validity and discriminant validity. From Table 1, we can see that the factor loading of each item is greater than 0.5 and their corresponding $\mathrm{P}$ values are all 0 , indicating that the convergence validity is good. The discriminant validity can be seen from the correlation coefficient matrix in Table 2, which shows that the correlation coefficients of all potential variables are less than the square root of AVE value of corresponding variable (the values in brackets in diagonal position); this indicates that the scale used in this study has good discriminant validity.

To control common method bias, this paper adopts the practice of Podsakoff et al (2003). Firstly, by discussing the content of the questionnaire with a number of scholars, unclear questions were removed to ensure that the respondents could clearly understand and answer the questions; then, several reverse questions were added and the order of the items was randomized to reduce errors caused by the respondents' inertia. Furthermore, the Harman's single factor method was used to test the common method bias problem. The results showed that the explanation rate of the first factor was $38.412 \%$, which was less than the critical standard of $40 \%$, meaning that not all variables formed a single high-order factor: this indicated that the common method bias problem is not serious and does not affect the conclusions of this study.

\section{The Main Effect}

In order to control the influence of other variables on knowledge innovation, this paper selects gender, age, educational background, position, job, industry, and team size as control variables. The mean value, standard deviation, and correlation coefficient of each variable are shown in Table 2 . As can be seen from Table 2, age, education background, team position, and participation time are significantly related to knowledge sharing and knowledge innovation. Positive emotion was significantly correlated 
Table 3. Multi-level hierarchical regression analysis

\begin{tabular}{|c|c|c|c|c|c|c|c|}
\hline \multirow[t]{2}{*}{ Variable } & \multicolumn{3}{|c|}{$\begin{array}{l}\text { Knowledge sharing } \\
\text { (KS) }\end{array}$} & \multicolumn{4}{|c|}{$\begin{array}{l}\text { Knowledge innovation } \\
\text { (KC) }\end{array}$} \\
\hline & Model 1 & Model 2 & Model 3 & Model 4 & Model 5 & Model 6 & Model 7 \\
\hline $\begin{array}{l}\text { Controlling variable: } \\
\text { Age }\end{array}$ & $0.118^{*}$ & 0.08 & 0.058 & 0.076 & 0.033 & 0.027 & 0 \\
\hline Education & $-0.157^{*}$ & -0.087 & -0.111 & -0.127 & -0.047 & -0.089 & -0.026 \\
\hline Position & 0.089 & -0.025 & 0.091 & $0.068^{*}$ & -0.062 & 0.069 & 0.011 \\
\hline Participation time & 0.073 & 0.062 & 0.065 & -0.013 & -0.025 & -0.02 & -0.06 \\
\hline Positive emotion(AE) & & $0.425^{* * *}$ & & & $0.484 * * *$ & & \\
\hline Negative emotion(DE) & & & $-0.263 * * *$ & & & $-0.214 * * *$ & \\
\hline $\begin{array}{l}\text { Knowledge } \\
\text { sharing(KS) }\end{array}$ & & & & & & & $0.642 * * *$ \\
\hline $\mathbf{R}^{2}$ & 0.045 & 0.215 & 0.161 & 0.021 & 0.282 & 0.112 & 0.485 \\
\hline $\mathbf{F}$ & $5.059 * * *$ & $23.663 * * *$ & $16.527 * * *$ & 2.294 & $33.826^{* * *}$ & $10.851 * * *$ & $81.298 * * *$ \\
\hline
\end{tabular}

Note:*denotes $p<0.05 ;{ }^{* *}$ denotes $p<0.01$.

with knowledge sharing $(\mathrm{r}=0.446, \mathrm{P}<0.01)$ and knowledge innovation $(\mathrm{r}=0.382, \mathrm{P}<0.01)$; negative emotion was significantly correlated with knowledge sharing $(\mathrm{r}=-0.325, \mathrm{P}<0.01)$ and knowledge innovation $(\mathrm{r}=-0.283, \mathrm{P}<0.01)$; knowledge sharing was significantly correlated with knowledge innovation $(\mathrm{r}=0.647, \mathrm{P}<0.01)$; and team trust was significantly correlated with knowledge innovation $(\mathrm{r}=0.692, \mathrm{P}<0.01)$.

To test $\mathrm{H} 1$ to $\mathrm{H} 3$, we used positive emotion and negative emotion as independent variables and knowledge sharing and knowledge innovation as dependent variables. In addition, the data analysis results obtained after controlling age, education, position, and participation time are shown in Table 3. As shown in Table 3, the values of the models are all significant at the level of $P<0.01$, indicating that these models are meaningful. In Model 5, the regression coefficient of positive emotion on knowledge innovation was significant $(\mathrm{B}=0.425, \mathrm{P}<0.001$, B stands for the non-standardized regression coefficient), and in model 6 , the regression coefficient of negative emotion on knowledge innovation was significant $(\mathrm{B}=-0.214, \mathrm{P}<0.001)$. The results support $\mathrm{H} 1$ and $\mathrm{H} 2$, indicating that positive emotion has a significant positive effect on knowledge innovation while negative emotion has a significant negative effect on knowledge innovation. In Model 7, the regression coefficient of knowledge sharing on knowledge innovation is significant $(\mathrm{B}=0.259, \mathrm{P}<0.001 ; \mathrm{B}=0.34, \mathrm{P}<$ 0.001 ), indicating that knowledge sharing has a significant positive impact on knowledge innovation. The analysis results support H3.

\section{The Mediating Effect of Knowledge Sharing}

To test the mediating role of knowledge sharing, based on Kenny et al. (1998)'s method, this paper tests whether the mediating effect satisfies the following four conditions: (1) The independent variable and the dependent variable are significantly correlated; (2) The independent variable and the mediating variable are significantly correlated; (3) The mediating variable and the dependent variable are significantly correlated; (4) The direct effect, that is, if the independent variable has no significant effect on the dependent variable, there is complete mediating effect. Otherwise, it indicates that there is a partial mediating effect. The results for the first and second steps of the test are shown in Table 2. As shown in Table 2, positive emotion (independent variable) is significantly correlated with knowledge innovation (dependent variable) $(\mathrm{B}=0.382, \mathrm{P}<0.01)$ and negative emotion (independent 
Table 4. The mediating effect of knowledge sharing and the $95 \%$ confidence interval

\begin{tabular}{|l|l|l|l|l|l|}
\hline Path & Effects & Estimates & SE & Boot LLCI & Boot ULCI \\
\hline \multirow{4}{*}{ AE-KS-KC } & Indirect effects & 0.227 & 0.0442 & 0.1489 & 0.3195 \\
\cline { 2 - 6 } & Direct effects & 0.257 & 0.034 & 0.1902 & 0.3238 \\
\cline { 2 - 6 } & Total effects & 0.484 & 0.0387 & 0.408 & 0.56 \\
\hline \multirow{3}{*}{ DE-KS-KC } & Indirect effects & -0.2139 & 0.0322 & -0.2772 & -0.1507 \\
\cline { 2 - 6 } & Direct effects & -0.0517 & 0.0261 & -0.1029 & -0.0005 \\
\cline { 2 - 6 } & Total effects & -0.1622 & 0.0332 & -0.2324 & -0.0997 \\
\hline
\end{tabular}

Note: 5,000 samplings

variable) is significantly correlated with knowledge innovation (dependent variable) $(\mathrm{B}=-0.283$, $\mathrm{P}<0.01$ ). In the second step, as shown in Table 2, positive emotions (independent variables) were significantly positively correlated with knowledge sharing (mediating variables) $(\mathrm{B}=0.446, \mathrm{P}<$ 0.01 ) while negative emotions (independent variables) were significantly negatively correlated with knowledge sharing (mediating variables) $(\mathrm{B}=-0.325, \mathrm{P}<0.01)$. The results of the third and fourth steps of the test are shown in Table 3. The analysis results for Model 7 in Table 3 show that knowledge sharing and knowledge innovation are significantly positively correlated $(\mathrm{B}=0.642, \mathrm{P}<0.001)$; Models 5 and 6 in Table 3 show that positive emotions are significantly correlated with knowledge innovation $(\mathrm{B}=0.484, \mathrm{P}<0.001)$, and negative emotions are significantly correlated with knowledge innovation $(\mathrm{B}=-0.214, \mathrm{P}<0.001)$. The results show that knowledge sharing partially mediates the relationship between positive emotions and knowledge innovation, and knowledge sharing partially mediates the relationship between negative emotions and knowledge innovation. As such, H4 and H5 are supported. To verify whether the mediating effect is significant, this paper uses SPSS (process 3.4) (model 4) developed by Hayes. The mediating effect of knowledge sharing on positive emotion and knowledge innovation was 0.227 ; the confidence interval was $(0.1489,0.3195)$, not including zero: this result indicates that the mediating effect was significant. The mediating effect of knowledge sharing on negative emotion and knowledge innovation was -0.2139 ; its confidence interval was $(-0.2772$, -0.1507), excluding zero: this result indicates that the mediating effect was significant (see Table 4).

\section{The Moderating Role of Team Trust in the Relationship between Knowledge Sharing and Knowledge Innovation}

This paper adopts the hierarchical regression method to test H6, that is, team trust plays a moderating role in the positive relationship between knowledge sharing and knowledge innovation. To reduce the correlation between the interaction term and the main effect, we centered the independent variable and the moderator. In the hierarchical regression, we use knowledge innovation as the dependent variable and input the following variables in the model: (1) control variables; (2) the two main effects (knowledge sharing and team trust); (3) the product term of knowledge sharing and team trust. As Model 3 in Table 5 shows, the product term of knowledge sharing and team trust reach the significant level $(\mathrm{B}=0.12, \mathrm{P}<0.001)$, which indicates the moderating effect of team trust is tested, thus supporting H6.

To explain the moderating effect, the results of the regression analysis are shown in Figure 2. To sum up, the analysis results shown in Table 5 and Figure 2 support H6: that is, team trust plays a moderating role in the relationship between knowledge sharing and knowledge innovation. It can be seen from Figure 2 that the slope of the straight line is positive regardless of whether team trust is at a low or high level, which means that the higher the degree of knowledge sharing among individuals, the higher the knowledge innovation; with the improvement of team trust, the slope of the straight 
Table 5. The moderating role of team trust in the relationship between knowledge sharing and knowledge innovation

\begin{tabular}{|c|c|c|c|c|c|c|c|c|c|}
\hline \multirow{2}{*}{$\begin{array}{l}\text { Variable } \\
\begin{array}{l}\text { Step one: Control } \\
\text { variable }\end{array}\end{array}$} & \multicolumn{9}{|c|}{ Knowledge innovation( $\mathrm{KC}$ ) } \\
\hline & Model 1 & Model 2 & Model 3 & Model 4 & Model 5 & Model 6 & Model 7 & Model 8 & Model 9 \\
\hline Age & $0.076^{*}$ & -0.018 & -0.004 & -0.014 & -0.024 & -0.011 & -0.017 & -0.023 & -0.01 \\
\hline Education & $-0.127^{*}$ & -0.013 & -0.02 & -0.01 & 0.0061 & -0.001 & -0.031 & -0.011 & -0.017 \\
\hline Position & 0.068 & 0.074 & $0.085^{*}$ & 0.05 & 0.02 & 0.032 & $0.131 * *$ & 0.075 & 0.086 \\
\hline Participation time & -0.013 & -0.042 & -0.046 & -0.021 & -0.043 & -0.046 & -0.017 & -0.042 & -0.046 \\
\hline \multicolumn{10}{|l|}{ Step two: Main effect } \\
\hline $\begin{array}{l}\text { Positive } \\
\text { emotion(AE) }\end{array}$ & & & & $0.269 * * *$ & $0.205^{* * *}$ & $0.197 * * *$ & & & \\
\hline $\begin{array}{l}\text { Negative } \\
\text { emotion(DE) }\end{array}$ & & & & & & & $-0.075^{* *}$ & -0.027 & $-0.038 * * *$ \\
\hline $\begin{array}{l}\text { Knowledge } \\
\text { sharing(KS) }\end{array}$ & & $0.381 * * *$ & $0.402^{* * * *}$ & & $0.321 * * *$ & $0.343^{* * *}$ & & $0.371 * * *$ & $0.389^{* * * *}$ \\
\hline Team trust(CT) & & $0.395 * * *$ & $0.455^{* * *}$ & $0.535 * * *$ & $0.354 * * *$ & $0.113^{* * *}$ & $0.609^{* * * *}$ & $0.39 * * *$ & $0.45^{* * *}$ \\
\hline \multicolumn{10}{|c|}{ Step three: Moderating effect } \\
\hline $\begin{array}{l}\text { knowledge } \\
\text { sharing*team trust }\end{array}$ & & & $0.12 * * *$ & & & $0.113^{* * *}$ & & & $0.123^{* * * *}$ \\
\hline $\mathbf{R}^{2}$ & 0.021 & 0.591 & 0.616 & 0.565 & 0.628 & 0.65 & 0.506 & 0.592 & 0.611 \\
\hline $\mathbf{F}$ & 2.294 & $103.389^{* * *}$ & $98.313 * * *$ & $27.831 * * *$ & $103.48^{* * *}$ & $99.49 * * *$ & $73.464^{* * *}$ & $88.881^{* * *}$ & $86.719 * * *$ \\
\hline
\end{tabular}

Note: ${ }^{*}<0.05 ;{ }^{* *}<0.01 ; * * *<0.001$ (two-tailed).

Figure 2. The moderating effect of team trust on the relationship between knowledge sharing and knowledge innovation

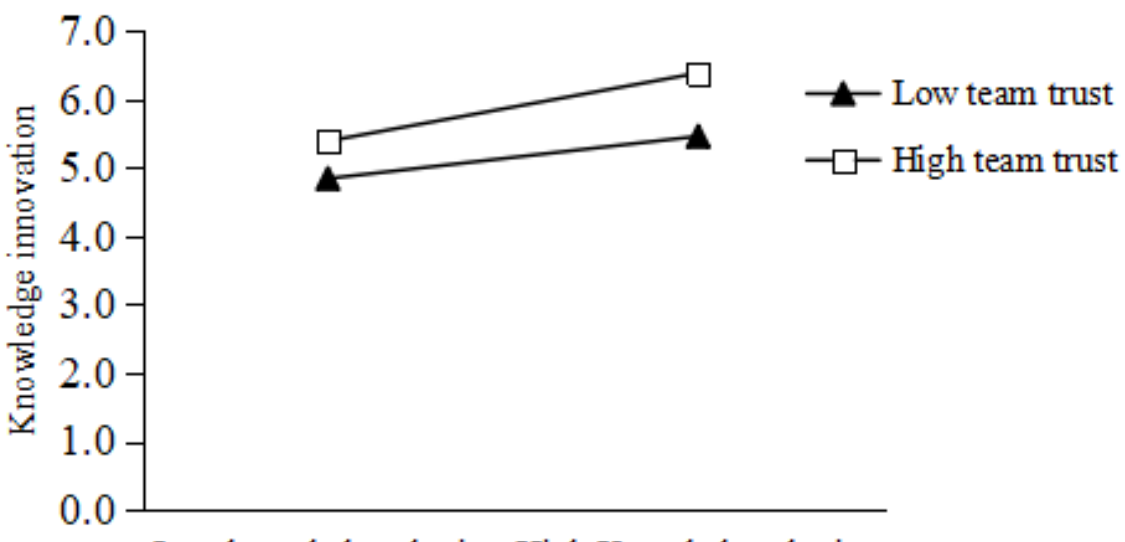

Low knowledge sharing High Knowledge sharing 
Table 6. Results of model analysis

\begin{tabular}{|l|l|l|l|l|l|}
\hline Model 14 & Coefficient & SE & P-values & LLCI & ULCI \\
\hline Constant & 5.5971 & 0.1192 & 0 & 5.3627 & 5.8315 \\
\hline AE & 0.1967 & 0.0304 & 0 & 0.1371 & 0.2564 \\
\hline KS & 0.3434 & 0.0367 & 0 & 0.02712 & 0.4156 \\
\hline CT & 0.4121 & 0.037 & 0 & 0.3394 & 0.4849 \\
\hline KS*CT & 0.1126 & 0.0216 & 0 & 0.0702 & 0.1551 \\
\hline
\end{tabular}

line increases, which indicates that team trust has a positive moderating effect on the relationship between knowledge sharing and knowledge innovation.

\section{The Moderated Mediating Effect}

In this paper, the paper adopts the method proposed by Hayes to test the moderated mediating effect using the bootstrap method. Among the 74 theoretical models of the bootstrap test program developed by Hayes, the research model in this paper corresponds to model 14. The paper uses SPSS macro (process 3.4) (model 14, $\mathrm{n}=5,000$ ) developed by Hayes in 2018 to conduct conditional process analysis. The test results are shown in Table 6 and Table 7. Table 6 shows that the interaction between knowledge sharing and team trust has a significant effect $(B=0.1126, P=0$, and the $95 \%$ confidence interval of the bootstrap test is $(0.0702,0.1551)$, which does not include zero, indicating that the influence of positive emotion on knowledge innovation through knowledge sharing is moderated by team trust. Therefore, $\mathrm{H} 6$ in this paper is further verified. Table 7 shows that when the team trust level is high (one standard deviation higher than the average, $\mathrm{B}=0.4486$, the confidence interval of bootstrap test is $(0.3624,0.5348)$, excluding zero), the effect of knowledge sharing on knowledge innovation is lower than that of team trust level (one standard deviation below the mean, $\mathrm{B}=0.2451$, and the confidence interval of bootstrap test is $(0.1678,0.3223))$, excluding zero. Therefore, compared with when team trust levels are low, knowledge sharing at a high level of team trust has a greater impact on knowledge innovation. Table 7 shows that the confidence interval of the bootstrap test for different levels of team trust does not contain 0 , indicating that the indirect path of the influence of positive emotion on knowledge innovation through knowledge sharing is significant and the mediating role of knowledge sharing exists - that is, team trust level plays a moderating role and the mediating effect of knowledge sharing on knowledge innovation does exist, and H7 is supported.

Table 8 shows that the interaction between knowledge sharing and team trust has a significant effect $(\mathrm{B}=0.1233, \mathrm{P}=0$, and the $95 \%$ confidence interval of bootstrap test is $(0.0789,0.1677))$, which does not include zero, indicating that the influence of negative emotion on knowledge innovation through knowledge sharing is moderated by team trust. Therefore, H6 in this paper is further confirmed.

Table 7. The influence of positive emotion on knowledge innovation through knowledge sharing at different levels of information sharing

\begin{tabular}{|c|c|c|c|c|}
\hline CT & KC & & & \\
\hline & Effect & $\mathrm{SE}$ & LLCI & ULCI \\
\hline low(-1 SD) & 0.2451 & 0.0393 & 0.1678 & 0.3223 \\
\hline moderate(SD) & 0.3468 & 0.0368 & 0.2745 & 0.4191 \\
\hline $\operatorname{high}(+1$ SD) & 0.4486 & 0.0439 & 0.3624 & 0.5348 \\
\hline
\end{tabular}

Note: SD denotes standard deviation; -1SD denotes subtracting a standard deviation; +1SD denotes adding a standard deviation. 
Table 8. Results of model analysis

\begin{tabular}{|l|l|l|l|l|l|}
\hline Model 14 & Coefficient & SE & P-Values & LLCI & ULCI \\
\hline Constant & 5.5064 & 0.1244 & 0 & 5.262 & 5.7508 \\
\hline DE & -0.0378 & 0.0228 & 0.0979 & -0.0826 & 0.007 \\
\hline KS & 0.3887 & 0.038 & 0 & 0.0 .314 & 0.4634 \\
\hline CT & 0.4503 & 0.0381 & 0 & 0.3754 & 0.5253 \\
\hline KS ${ }^{*}$ CT & 0.1233 & 0.0226 & 0 & 0.0789 & 0.1677 \\
\hline
\end{tabular}

Table 9 shows that when the team trust level is high (one standard deviation higher than the average, $\mathrm{B}=0.5038$, the confidence interval of the bootstrap test is $(0.4154,0.5923)$, excluding zero), the effect of knowledge sharing on knowledge innovation is significantly higher than when the team trust level is low (one standard deviation below the average, $\mathrm{B}=0.281$, confidence interval of bootstrap test is $(0.1998,0.3622)$, excluding zero). Therefore, compared with when the level of team trust is low, knowledge sharing has a greater impact on knowledge innovation when the team trust level is high. Table 9 shows that the confidence intervals of the bootstrap test for different levels of team trust do not contain 0 , which indicates that the indirect path of the influence of negative emotions on knowledge innovation through knowledge sharing is significant and the mediating role of knowledge sharing exists - that is, team trust level plays a moderating role and the mediating effect of knowledge sharing on knowledge innovation does exist, and $\mathrm{H} 8$ is supported.

\section{DISCUSSION}

This study confirms that individual emotion is an important antecedent of individual knowledge innovation. The empirical results show that positive emotion has a significant positive predictive effect on individual knowledge innovation, while negative emotion has a significant negative effect on individual knowledge innovation. The results of this paper are consistent with the views of some scholars: that is, when individuals are in a positive emotional state, their initiative and enthusiasm to solve problems are enhanced. They actively collect relevant information and are willing to coordinate with others, which is conducive to knowledge innovation (Fredrickson, 2001; George \& Zhou, 2007). However, the results of this paper suggest that even if individuals are in a state of negative emotions, they can sensitively identify the dangerous signals in the external environment which promotes the identification and solution of problems (Eastwood et al., 2012; Timothy \& Selma, 2015). However, the higher the degree of negative emotions, the more the fluency, flexibility, and creativity of individual thinking will be inhibited, thus hindering knowledge innovation (Timothy \& Selma, 2015).

Table 9. The influence of negative emotion on knowledge innovation through knowledge sharing at different levels of information sharing

\begin{tabular}{|c|c|c|c|c|}
\hline CT & $\mathrm{KC}$ & & & \\
\hline & Effect & SE & LLCI & ULCI \\
\hline $\operatorname{low}(-1$ SD) & 0.281 & 0.0413 & 0.1998 & 0.3622 \\
\hline moderate(SD) & 0.3924 & 0.0368 & 0.23176 & 0.4672 \\
\hline high(+1 SD) & 0.5038 & 0.0439 & 0.4154 & 0.5923 \\
\hline
\end{tabular}

Note: SD denotes standard deviation; -1SD denotes subtracting a standard deviation; +1SD denotes adding a standard deviation. 
Second, knowledge sharing mediates the relationship between individual emotion and knowledge innovation. The results show that individuals' positive emotions have a significant positive predictive effect on knowledge sharing, and positive emotions have a positive impact on individuals' knowledge innovation through knowledge sharing; individuals' negative emotions have a significant negative predictive effect on knowledge sharing and negative emotions also have a significant negative impact on individuals' knowledge innovation through knowledge sharing. In the negative emotional state, the individual experiences feelings of anger, annoyance, disgust, and irritability, which makes it difficult for them to recover their peace of mind, reduces their enthusiasm for work, and dampens creativity, thus affecting their knowledge innovation performance (Seth et al., 2013). This study introduces knowledge sharing as a key factor, discusses the relationship between individual emotions and knowledge sharing, and uncovers the "black box" in which individual emotions affect individual knowledge innovation. All of these findings have important theoretical significance.

Furthermore, team trust plays a moderating role in the relationship between knowledge sharing and knowledge innovation. There is a consensus that when the joint effects of individual factors and group factors are considered, research on knowledge innovation can achieve results that are more valuable. The empirical results show that team trust plays a positive moderating role in the relationship between knowledge sharing and knowledge innovation - that is, when team trust increases, the impact of knowledge sharing on knowledge innovation is enhanced. Regardless of whether the emotions are positive, such as happiness, enthusiasm, and activeness, or negative, such as disgust, irritability, and anger, individual emotions are moderated by team trust. The higher the team trust, the stronger the impact of positive and negative emotions on knowledge innovation through knowledge sharing. This shows that in management practice, team trust is an important factor that requires more attention. The stronger the team trust, the more optimistic the employees will be toward the working environment, intensifying the interaction between employees and other members: this is conducive to promoting knowledge innovation.

\section{CONCLUSION}

\section{Theoretical Contributions}

In this paper, the authors construct a moderated mediation model to explore the mechanism by which emotion influences knowledge innovation. Research shows that knowledge sharing serves as an important way for individuals' emotion mechanism to function. An individual's emotions can directly affect their knowledge sharing, which is moderated by the trust atmosphere of the team. The main theoretical contributions of this study include the following aspects.

Although the research on knowledge innovation is increasingly rich, studies on individual knowledge innovation from the emotional perspective remain scarce. This paper examines the influence of emotion on knowledge innovation through knowledge sharing. It responds to the research on emotion and creativity. Moreover, the findings show that the relationship between emotion and knowledge innovation is positively moderated by team trust. This study extends the research on knowledge sharing. It clarifies the relationship between emotion and knowledge sharing based on the individual emotional state. The proposed theoretical model is closer to reality. The empirical study tests the mediating role of knowledge sharing in the influence of emotions on knowledge innovation. This study makes an important expansion of and beneficial supplement to the existing research and offers a new perspective.

Emotional management has a unique value for knowledge innovation. In management practice, we should pay attention to the individual emotional state and incorporate emotional management into knowledge innovation management. During the process of individual knowledge innovation, positive emotion promotes knowledge innovation while negative emotion hinders knowledge innovation. However, when an individual is in a negative emotional state, knowledge sharing can also promote 
individual knowledge innovation and individual efforts and persistence by enhancing team trust to promote knowledge innovation. Combining emotional event management, attitude management, and the management of leaders' emotional characteristics, we can introduce positive emotions into work and provide a method to control negative emotions, e.g. by preventing the transmission and spreading of negative emotions. Beneficial interaction among the groups promotes the formation of a positive knowledge-sharing atmosphere and enhances divergent thinking by the team, which leads to the generation of novel ideas.

Team trust is the degree of trust among individuals in a group. The introduction of team trust as a specific situational variable in the relationship between "knowledge sharing and knowledge innovation" not only provides strong positive support for the knowledge sharing theory, but also enriches the theoretical knowledge on team trust. By introducing team trust as a moderating variable, this paper clarifies the theoretical boundary of the influence of emotion on knowledge innovation and enriches the research explaining the role of emotion in knowledge innovation. It not only expands the scope of explanation of the antecedents of knowledge sharing, but also explains why individuals in negative and positive emotional states are more prone to knowledge innovation.

\section{Implications}

This paper examines the mechanism underlying the influence of positive and negative emotions on knowledge innovation. The results show that knowledge sharing plays a significant and partly mediating role in the relationship between positive emotion and innovation and that between negative emotion and innovation. Moreover, team trust positively moderates the relationship between knowledge sharing and knowledge innovation. These findings have important theoretical and practical significance. Given that the actions of managers can affect individuals' emotions in the workplace, managers should be aware that the emotions generated by subordinates in their work settings have an important impact on knowledge innovation. First, managers should enable their subordinates to have emotional experiences that are more positive and appropriately support them when they are experiencing negative emotions. For example, the Loongson team of the Chinese Academy of Sciences improves the team's innovation enthusiasm by arousing team members' positive emotions (Tang et al., 2011). Second, managers should provide an interactive working environment. An environment with rich interpersonal interactions, such as knowledge sharing, can make individuals in different emotional states to recognize and obtain resources and therefore achieve better knowledge innovation. It is worth noting that knowledge sharing is important to ensure the development of cooperation and realization of goals. For example, during the collaboration between Toyota and GM, both sides were reluctant to share their own knowledge with each other. This made it difficult to achieve the goal of cooperation. Consequently, the cooperation finally broke up and, needless to say, knowledge innovation was not realized (Manhart \& Thalmann, 2015).

In management practice, managers should pay attention to the key factors in the process of individual knowledge innovation. Through training and other ways, managers can improve the emotion management ability of individuals, cultivate their positive emotions, enhance their confidence in knowledge innovation activities, promote mutual trust within teams, and then stimulate the knowledge innovation behavior in innovation activities. Costa and her colleagues collected data from 112 teams in 2001. Their study also showed that if a team was full of trust atmosphere, the enthusiasm of individual members for innovation would affect the creativity of the whole team. As such, team trust is regarded as an important guarantee for the smooth progression of team knowledge innovation. Based on a case study of the aviation sector, Jordan and Lowe (2004) found that when the team trust was low, knowledge exchange among members decreased, which affected knowledge innovation. For example, Pearce observed that a customer manager of an investment company needed to spend extensive time filling in a lot of reports, collecting data, and proving the validity of his decisions (Ashport, 1990). In essence, this serious waste of human resources resulted from the distrust of his team members, which is not conducive to organizational innovation (Luthans et al., 2005). 


\section{Limitations and Future Research}

There are still some limitations to this study, which must be addressed through follow-up research. First, in terms of research methods, this study adopts a cross-sectional questionnaire survey method. Although some meaningful findings have been obtained, it is still difficult to test the dynamic influence of positive and negative emotions on individual knowledge innovation. Second, this study introduces knowledge sharing and team trust into the analysis framework, which only reveals the tip of iceberg of the mechanism of positive emotion and negative emotion on individual knowledge innovation behavior. Follow-up research may introduce new mediating variables to increase the explanatory power of the model. Third, individual knowledge innovation is the result of the complex interaction of factors at the individual, group, and organizational level. As such, exploration of the influencing factors of knowledge sharing and its process from only the individual level cannot provide insights into such issues as the cross-level moderating effect of team trust as well as how individuals interact with group contexts.

\section{ACKNOWLEDGMENT}

This research was supported by the NSFC [grant numbers 72002088]; Jiangxi Natural Science Fund [grant numbers 20192BAB207010]; Jiangxi Social Science Foundation [grant numbers 20TQ02]; Science and Technology Project Founded by the Education department of Jiangxi Province [grant numbers GJJ190292]; Jiangxi Province Postgraduate Innovation Special Fund Project [grant numbers YC2019-B090]; Teaching reform research project of Jiangxi province degree and postgraduate education[grant numbers JXYJG-2020-085]. 


\section{REFERENCES}

Akgun, A. E., Byren, J., \& Keskin, H. (2005). Knowledge networks in new product development projects: A transactive memory perspective. Information \& Management, 10(8), 1105-1120. doi:10.1016/j.im.2005.01.001

Anand, I. M., \& Gaur, S. S. (2019). Consequences of consumers' emotional responses to government's green initiatives: Insights from a scenario-based experimental study. Management of Environmental Quality, 30(1), 243-259. doi:10.1108/MEQ-02-2018-0045

Baas, M., De Dreu, C. K. W., \& Nijstad, B. A. (2008). A meta-analysis of 25 years of mood-creativity research: Hedonic tone, activation, or regulatory focus? Psychological Bulletin, 134(6), 779-806. doi:10.1037/a0012815 PMID:18954157

Baas, M., Roskes, M., Sligte, D., Nijstad, B. A., \& De Dreu, C. K. W. (2013). Personality and creativity: The dual pathway to creativity model and a research agenda. Social and Personality Psychology Compass, 7(10), 732-748. doi:10.1111/spc3.12062

Bilian, L., \& Charalampos, M. (2016). Leaders' responses to creative deviance: Differential effects on subsequent creative deviance and creative performance. The Leadership Quarterly, 27(4), 537-556. doi:10.1016/j. leaqua.2015.09.001

Bock, G. W., Zmud, R. W., Kim, Y. G., \& Lee, J. N. (2005). Behavioral intention formation in knowledge sharing: Examining the roles of extrinsic motivators, social-psychological forces, and organizational climate. Management Information Systems Quarterly, 29(1), 87-111. doi:10.2307/25148669

Buric, I., \& Macuka, I. (2018). Self-efficacy, emotions and work engagement among teachers: A two wave crosslagged analysis. Journal of Happiness Studies, 19(7), 1917-1933. doi:10.1007/s10902-017-9903-9

Cabrera, Á., Collins, W. C., \& Salgado, J. F. (2006). Determinants of individual engagement in knowledge sharing. International Journal of Human Resource Management, 17(2), 245-264.

Cao, Y., Sun, H. L., Jiang, Z. Y., \& Ruan, X. (2016). A study of fuzzy front end uncertainty, knowledge sharing and new product development performance. Science Research Management, 7(5), 24-32.

Cheung, S. Y., Gong, Y., Wang, M., Zhou, L., \& Shi, J. (2016). When and how does functional diversity influence team innovation? The mediating role of knowledge sharing and the moderation role of affect-based trust in a team. Human Relations, 69(7), 1507-1531. doi:10.1177/0018726715615684

Cohen, W. M., \& Levinthal, D. A. (1990). Absorptive capacity: A new perspective on learning and innovation. Administrative Science Quarterly, 35(1), 128-152. doi:10.2307/2393553

Costa, A. C., Roe, R. A., \& Taillieu, T. (2001). Trust within teams: The relation with performance effectiveness. European Journal of Work and Organizational Psychology, 10(3), 225-244. doi:10.1080/13594320143000654

Costigan, R. D., Ilter, S. S., \& Berman, J. J. (1998). A multi-dimensional study of trust in organizations. Journal of Managerial Issues, 10(3), 303-317.

Davis, M. A. (2007). Understanding the relationship between mood and creativity: A meta-analysis. Organizational Behavior and Human Decision Processes, 108(1), 25-38. doi:10.1016/j.obhdp.2008.04.001

Davis, M. A. (2009). Understanding the relationship between mood and creativity: A meta-analysis. Organizational Behavior and Human Decision Processes, 108(1), 25-38. doi:10.1016/j.obhdp.2008.04.001

Deas, A., \& Coetzee, M. (2020). Psychological contract, career concerns, and retention practices satisfaction of employees: Exploring interaction effects. Current Psychology (New Brunswick, N.J.), 39(4), 1990-1998. doi:10.1007/s12144-020-00660-0

Deortentiis, P. S., Summers, J. K., \& Ammeter, A. P. (2013). Cohesion and satisfaction as mediators of the team trust-team effective-ness relationship. Career Development International, 18(5), 521-543. doi:10.1108/ CDI-03-2013-0035

Eastwood, J. D., Frischen, A., Fenske, M. J., \& Smilek, D. (2012). The unengaged mind: Defining boredom in terms of attention. Perspectives on Psychological Science, 7(5), 482-495. doi:10.1177/1745691612456044 PMID:26168505 
Nicholson, Aybek, \& O'Daly. (2015). Emotion-motion interactions in conversion disorder: An fmri study. Journal of Neurology, Neurosurgery, and Psychiatry.

Erdem, F., \& Ozen, J. (2003). Cognitive and affective dimensions of trust in developing team performance. Team Performance Management, 9(5/6), 131-135. doi:10.1108/13527590310493846

Feng, J., Zhao, L., Jia, H., \& Shao, S. (2019). Silk Road economic belt strategy and industrial total-factor productivity: Evidence from Chinese industries. Management of Environmental Quality, 30(1), 260-282. doi:10.1108/MEQ-06-2018-0109

Fernández-Abascal, E. G., \& Díaz, M. D. M. (2013). Affective induction and creative thinking. Creativity Research Journal, 25(2), 213-221. doi:10.1080/10400419.2013.783759

Forgays, D. G., Forgays, D. K., \& Spielberger, C. D. (1997). Factor structure of the state-trait anger expression inventory. Journal of Personality Assessment, 69(3), 497-507. doi:10.1207/s15327752jpa6903_5 PMID:9501480

Fredrickson, B. L. (2001). The role of positive emotions in positive psychology. The broaden-and-build theory of positive emotions. The American Psychologist, 56(4), 218-226. doi:10.1037/0003-066X.56.3.218 PMID:11315248

George, J. M., \& Zhou, J. (2002). Understanding when bad moods foster creativity and good ones don't: The role of context and clarity of feelings. The Journal of Applied Psychology, 87(4), 687-697. doi:10.1037/00219010.87.4.687 PMID:12184573

George, J. M., \& Zhou, J. (2007). Dual tuning in a supportive context: Joint contributions of positive mood, negative mood and supervisory behaviors to employee creativity. Academy of Management Journal, 50(3), 605-622. doi:10.5465/amj.2007.25525934

Gergana, T. (2007). Absorptive capacity: Valuing a reconceptualization. Academy of Management Review, 32(3), 774-786. doi:10.5465/amr.2007.25275513

Gruber, T. R. (1995). Toward principles for the design of ontologies used for knowledge sharing? International Journal of Human-Computer Studies, 43(5-6), 907-928. doi:10.1006/ijhc.1995.1081

Guo, J., \& Zhao, Y. (2017). Co-workers make me creative: The impact of indirect networks on employee creativity-The moderating role of psychological safety. Human Resources Development of China, 8, 59-70.

Hansen, M. T. (1999). The search-transfer problem: The role of weak ties in sharing knowledge across organization subunits. Administrative Science Quarterly, 1(1), 82-111. doi:10.2307/2667032

Hansen, M. T. (2002). Knowledge networks: Explaining effective knowledge sharing in multiunit companies. Organization Science, 13(3), 232-248. doi:10.1287/orsc.13.3.232.2771

Hashim, K. F., \& Tan, F. B. (2015). The mediating role of trust and commitment on members' continuous knowledge sharing intention: A commitment-trust theory perspective. International Journal of Information Management, 35(2), 145-151. doi:10.1016/j.jinfomgt.2014.11.001

Hoegl, M., \& Gemuenden, H. G. (2001). Teamwork quality and the success of innovative projects: A theoretical concept and empirical evidence. Organization Science, 12(4), 435-449. doi:10.1287/orsc.12.4.435.10635

Huang, L., \& Luthans, F. (2015). Toward better understanding of the learning goal orientation-creativity relationship: The role of positive psychological capital. Applied Psychology, 64(2), 444-472. doi:10.1111/ apps. 12028

Huemer, L. (2014). Creating cooperative advantage: The roles of identification, trust, and time. Industrial Marketing Management, 4(4), 564-572. doi:10.1016/j.indmarman.2014.02.011

Jong, B. A. D., \& Elfring, T. (2010). How does trust affect the performance of ongoing teams? The mediating role of reflexivity, monitoring, and effort. Academy of Management Journal, 53(3), 535-549. doi:10.5465/ amj.2010.51468649

Judge, T. A., \& Kammeyer-Mueller, J. D. (2012). Job attitudes. Annual Review of Psychology, 63(1), 341-367. doi:10.1146/annurev-psych-120710-100511 PMID:22129457 
Kaplan, S., LaPort, K., \& Waller, M. J. (2013). The role of positive affectivity in team effectiveness during crises. Journal of Organizational Behavior, 34(4), 473-491. doi:10.1002/job.1817

Kim, B.-J. (2019). Unstable Jobs Cannot Cultivate Good Organizational Citizens: The Sequential Mediating Role of Organizational Trust and Identification. International Journal of Environmental Research and Public Health, 16(7), 1102. doi:10.3390/ijerph16071102 PMID:30934804

Kipkosgei, F., Kang, S. W., \& Choi, S. B. (2020). A team-level study of the relationship between knowledge sharing and trust in kenya: Moderating role of collaborative technology. Sustainability, 12(4), 1615. doi:10.3390/ su12041615

Kjersti, B., Morten-Birkeland, N., Kathryn, M., \& Jarle, E. (2015). The relationship between psychological capital, job satisfaction, and safety perceptions in the maritime industry. Safety Science, 74, 27-36. doi:10.1016/j. ssci.2014.11.024

Kramer, R. M., \& Tyler, T. R. (1996). Trust in organizations: Frontiers of theory and research. SAGE Publications, Inc.

Li, Y., \& Wang, X. (2018). Seeking health information on social media: A perspective of trust, selfdetermination, and social support. Journal of Organizational and End User Computing, 30(1), 1-22. doi:10.4018/ JOEUC.2018010101

Liang, C., Chang, C., \& Rothwell, W. (2016). Influences of organizational culture on knowledge sharing in an online virtual community: Interactive effects of trust, communication and leadership. Journal of Organizational and End User Computing, 28(4), 15-32.

Liang, C., Chang, C.-C., Rothwell, W., \& Kuen-Ming, S. (2016). Influences of organizational culture on knowledge sharing in an online virtual community: Interactive effects of trust, communication and leadership. Journal of Organizational and End User Computing, 28(4), 15-32. doi:10.4018/JOEUC.2016100102

Lin, H.-C., Dang, T. T. H., \& Liu, Y.-S. (2016). CEO transformational leadship and firm performance: A moderated mediation model of TMT trust climate and environmental dynamism. Asia Pacific Journal of Management, 33(4), 981-1008. doi:10.1007/s10490-016-9468-x

Lin, L., \& Liang, X. (2009). The mediating effect of knowledge sharing between interpersonal interactions and innovation. Nankai Business Review, 2(1), 118-123.

Liu, W., Chen, X., Lu, X., \& Fan, X. (2021). Exploring the relationship between users' psychological contracts and their knowledge contribution in online health communities. Frontiers in Psychology, 12, 1-15. doi:10.3389/ fpsyg.2021.716702

Lowe, J. J. (2004). Protecting strategic knowledge: Insights from collaborative agreements in the aerospace sector. Technology Analysis and Strategic Management, 16(2), 241-259. doi:10.1080/09537320410001682900

Lundvall, B. A., \& Archibugi, D. (2001). The globalizing learning economy. Oxford University Press.

Luthans, F., Avolio, B. J., Walumbwa, F. O., Li, W., \& Tsui, A. (2005). The psychological capital of chinese workers: Exploring the relationship with performance. Management and Organization Review, 1(2), 249-271. doi:10.1111/j.1740-8784.2005.00011.x

Manhart, M., \& Thalmann, S. (2015). Protecting organizational knowledge: A structured literature review. Journal of Knowledge Management, 19(2), 190-211. doi:10.1108/JKM-05-2014-0198

Mayer, R. C., Davis, J. H., \& Schoorman, F. D. (1995). An integrative model of organizational trust. Academy of Management Review, 20(20), 709-734. doi:10.5465/amr.1995.9508080335

Nonaka, I. (1994). A dynamic theory of organizational knowledge creation. Organization Science, 5(1), 14-37. doi:10.1287/orsc.5.1.14

Peng, J., Quan, J., Zhang, G., \& Dubinsky, A. J. (2015). Knowledge sharing, social relationships, and contextual performance: The moderating influence of information technology competence. Journal of Organizational and End User Computing, 27(2), 58-73. doi:10.4018/joeuc.2015040103 
Podsakoff, P. M., Mackenzie, S. B., Lee, J. Y., \& Podsakoff, N. P. (2003). Common method biases in behavioral research: A critical review of the literature and recommended remedies. The Journal of Applied Psychology, 88(5), 879-903. doi:10.1037/0021-9010.88.5.879 PMID:14516251

Qu, R., Lin, W., Jie, S., \& Kan, S. (2015). Abusive leadership and employee creativity: The effect of employee self-concept. Management Review, 27(8), 90-101.

Reis, D. P. D., \& Puente-Palacios, K. (2018). Team effectiveness: The predictive role of team identity. RAUSP Management Journal, 54(2), 141-153. doi:10.1108/RAUSP-07-2018-0046

Reychav, I., \& Weisberg, J. (2013). Bridging intention and behavior of knowledge sharing. Journal of Knowledge Management, 14(2), 285-300. doi:10.1108/13673271011032418

Rhee, S. Y. (2007). Shared emotions and group effectiveness: The role of broadening-and-building interactions. Academy of Management Journal, 50(3), 605-622.

Rowe, G., Hirsh, J., \& Anderson, A. (2007). Positive affect increases the breadth of attentional selection. Proceedings of the National Academy of Sciences of the United States of America, 104(1), 383-388. doi:10.1073/ pnas.0605198104 PMID:17182749

Schwarz, N., \& Clore, G. L. (2003). Mood, misattribution, and judgments of well-being: Informative and directive functions of affective states. Journal of Personality and Social Psychology, 45(3), 513-523. doi:10.1037/00223514.45.3.513

Seo, M. G., Taylor, M. S., Hill, N. S., Zhang, X., Tesluk, P. E., \& Lorinkova, N. M. (2012). The role of affect and leadership during organizational change. Personnel Psychology, 65(1), 121-165. doi:10.1111/j.17446570.2011.01240.x

Siacotos, T. J. C. (1998). Trust, communication and creativity in new product development teams. Oregon State University.

Stata, R. (1989). Organizational Learning-The key to management innovation. MIT Sloan Management Review, 30(3), 63-74.

Stephens, J. P., \& Carmeli, A. (2016). The positive effect of expressing negative emotions on knowledge creation capacity and performance of project teams. International Journal of Project Management, 354(5), 862-873. doi:10.1016/j.ijproman.2016.03.003

Sun, S., \& Van Emmerik, H. I. (2015). Are proactive personalities always beneficial? Political skill as a moderator. The Journal of Applied Psychology, 100(3), 966-975. doi:10.1037/a0037833 PMID:25180658

Tang, C., Shu, A., \& Gong, Z. (2011). The social function of the positive mood and its influence on team creativity: The mediating effect of tacit knowledge sharing. Nankai Business Review, 14(4), 129-137.

Tsai, W. (2001). Knowledge transfer in organizational networks: Effects of network position and absorptive capacity on business unit innovation and performance. Academy of Management Journal, 44(5), 996-1004.

Tsai, W., \& Ma, W. (2020). Benchmarking, knowledge inertia, and knowledge performance in different network structures. Enterprise Information Systems, 14(5), 641-660. doi:10.1080/17517575.2019.1698059

Tu, Yang, \& Qi. (2016). The mechanism and path of learning goal orientation, knowledge sharing willingness and employees' creativity. Science of Science and Management of S\&T, 37(2), 161-171.

Tu, X., Qi, Z., Wang, Z., Zhao, Z., \& Xin, H. (2017). Knowledge workers' intrinsic motivation, knowledge sharing intention and creativity. Science Research Management, 38(10), 111-118.

Van Woerkom, M., \& Meyers, C. (2015). My strengths count! Effects of a strengths-based psychological climate on positive affect and job performance. Human Resource Management, 54(1), 81-103. doi:10.1002/hrm.21623

Walumbwa, F. O., Luthans, F., Avey, J. B., \& Oke, A. (2011). Retracted: Authentically leading groups: The mediating role of collective psychological capital and trust. Journal of Organizational Behavior, 32(1), 4-24. doi:10.1002/job.653

Wang, H., \& Yu, J. (2019). The effect of organizational creative climate on creative deviant behavior. Soft Science, 33(2), 126-129. doi:10.1016/j.ssci.2018.09.009 
Wang, S., \& Noe, R. A. (2010). Knowledge sharing: A review and directions for future research. Human Resource Management Review, 20(2), 115-131. doi:10.1016/j.hrmr.2009.10.001

Wang \& Wei-Tsong. (2016). Examining the influence of the social cognitive factors and relative autonomous motivations on employees' knowledge sharing behaviors. Decision Sciences, 47(3), 404-436.

Watson, D. (1988). Intraindividual and interindividual analyses of positive and negative affect: Their relation to health complaints, perceived stress, and daily activities. Journal of Personality and Social Psychology, 54(6), 1020-1030. doi:10.1037/0022-3514.54.6.1020 PMID:3397861

Weiss, H. M., \& Cropanzano, R. (1996). Affective events theory: A theoretical discussion of the structure, causes and consequences of affective experiences at work. Research in Organizational Behavior, 18(3), 1-74.

Woerkom, M. V., \& Meyers, M. C. (2015). My strengths count! Effects of a strengths-based psychological climate on positive affect and job performance. Human Resource Management, 54(1), 81-103. doi:10.1002/hrm.21623

Wu, C. H., Wu, W., Ma, S., Su, Y., \& Tsai, S. B. (2020). Organisational leadership style, network structure, and knowledge performance in online knowledge community organisations. Enterprise Information Systems, 4, 1-20.

Wu, W., Ma, S., Su, Y., \& Wu, C.-H. (2021). Double-layer learning, leaders' forgetting, and knowledge performance in online work community organizations. Journal of Organizational and End User Computing, 33(1), 92-117. doi:10.4018/JOEUC.2021010105

Xiao, F., Wang, L., Chen, Y., Zheng, Z., \& Chen, W. (2015). Dispositional and situational autonomy as moderators of mood and creativity. Creativity Research Journal, 27(1), 76-86. doi:10.1080/10400419.2015.992683

Xu, J., \& Song, C. (2018). Multilevel effects of group resources on individual knowledge sharing from the perspective of collective psychological capital. Science Research Management, 39(3), 101-109.

Ying, X. (2015). Research on chaxu atmosphere, perceived organizational support and tacit knowledge sharing. Science and Technology Management Research, 35(9), 133-139.

Zara, N., \& Waqar, J. S. (2018). Trust-based situation awareness: Comparative analysis of agent-based and population-based modeling. Complexity, 1-17.

Zhang, C., Wang, X., Li, D., \& Bo, W. (2017). The transmission mechanism of negative emotion and behavior intention in online shopping: Based on stress-and-coping and rumination theory. Journal of Central University of Finance \& Economics, 2, 84-92.

Zhao, X. (2020). Research on inhibiting mechanism of employee innovation behavior-from the perspective of negative emotion. Contemporary Economic Management, 8, 1-10.

Zou, L., \& Zhu, Y. W. (2020). Research on innovation performance in heterogeneous region: Evidence from yangtze economic belt in china. Complexity, 2020(2), 1-9. doi:10.1155/2020/8659134 
Chen Si-hua is a Professor at the College of Information Technology of Jiangxi University of Finance and Economics. He received his Ph.D. in Management in 2011 form Jiangxi University of Finance and Economics; Currently, he is a Vice Dean at the School of Information Technology in Jiangxi University of Finance and Economics. His research interests include Knowledge Management and E-Commerce. He is a Vice Executive Chairman of the China Information Economics Association.

Hua Xiao is a Ph.D. candidate of the Management Science and Engineering program at Jiangxi University of Finance and Economics. Currently, she is working at the library of Jiangxi Agricultural University. Her current research interests focus on E-Commerce and Knowledge Management.

He Wei received a Ph.D. degree in Management Science and Engineering from the Jiangxi University of Finance and Economics, Jiangxi Nanchang, China, in 2010. Now she is a Professor of Management at the Jiangxi University of Finance and Economics. Her current research interests include Organizational Theory, E-Commerce, and Professionalism.

Jian Mou is an associate professor in the School of Business, Pusan National University, South Korea. His research interests include big data analysis, social media, trust and risk issues in e-service, and information management. Dr. Mou's research has been published in Journal of the Association for Information Systems, Information and Management, International Journal of Information Management, Internet Research, Electronic Commerce Research, Information Processing and Management, Computers in Human Behavior, Information Technology and People, Behaviour and Information Technology, International Journal of Human-Computer Interaction, Journal of Retailing and Consumer Services, Information Development, International Journal of Mobile Communications, and The Electronic Library.

Mikko Siponen is a Professor of Information Systems at the University of Jyväskylä. He has served as the Vice Dean for Research, the Department Head, Vice Head, and as the Director of an IS Security Research Center. His degrees include Doctorate of Social Sciences, majoring in Applied Philosophy; MSc in Software Engineering; and a Ph.D. in Information Systems. He has received several million euros in research funding from corporations and many other funding bodies. He is an invited member of The Finnish Academy of Science and Letters.

Han Qiu is a Ph.D. candidate of the Management Science and Engineering program at Jiangxi University of Finance and Economics. His current research interests focus Information Technology and Knowledge Management.

Xu Feng is an Associate Professor of College of Management and Economics, Tianjin University. His research interests focus on Big Data Analysis in Finance and Economics. He serves as the Coordinating Editor of Journal of Management Science and Engineering, and the Associate Editor of Finance Research Letters. 